\title{
A Decisive Account of Specific Forms of Psychosocial Privation as Cause of Schizophrenia
}

\section{Saunders V*}

Independent researcher, London, UK

*Corresponding author: Valerie Saunders, Independent Researcher, London, UK, Email: mdw1886@yahoo.co.uk

\section{Research Article}

Volume 5 Issue 1

Received Date: May 20, 2021

Published Date: June 25, 2021

DOI: $10.23880 / \mathrm{mhrij}-16000144$

\section{Abstract}

Aim: To demonstrate that evidence of psychosocial privation as cause has already been available for decades through previously published data. To supplement published evidence with additional original data that ensures comprehensive and precise explanation of cause.

Methods: Triangulation was used. Firstly, evidence was provided through analyzing government epidemiological schizophrenia rates for the UK and Canada. Published data from case studies was re-interpreted, in tandem with original data from community relationships as an example of normalcy. Such data was then compared with a precise recently published list of all human psychosocial need. Finally, original evidence from an analysis of further community based case studies was provided.

Results: It was shown that cause is complex and multifactorial as set out in a figure. This has contributed to previous researchers not being able to determine cause with certainty. Through re-interpreting case studies data through contemporary information about human psychosocial needs, it was revealed that sufferers are not able to form appropriate schemas due to abnormal parental behaviours that prevent psychosocial environment comprehension and rule formation leading to conflict, confusion, and inability to mentally organize information. This also explains increased rates in migrants; it is due to different norms (schemas) between societies of origin and destination causing conflict and confusion.

Conclusion: Parents have mental health problems leading to the intergenerational transmission of abnormal familial culture through learned deviant behaviour. Any such psychosocial privation is a form of child abuse. The role of the extended family can potentially be preventative. Schizophrenia is a psychosocial privation problem accounted for mostly through social science paradigms.

Clinical Implications: Understanding cause has important ramifications for prevention and improving treatment.

Keywords: Child abuse; Cognitive psychology; Epidemiology rates; Psychosocial privation; Psychosocial need; Schemas; Schizophrenia; Sociology 


\section{Mental Health \& Human Resilience International Journal}

\section{Introduction}

Arguably schizophrenia is the most serious of all mental health problems due to the severity of impact on the sufferer, family and society. In spite of this, no definite cause has been documented by medical scientists to date although published clinical evidence of cause has been available for decades but not recognized as such. It could be argued that this is because the medical science approach to mental health research is inadequate and that investigation and analysis of mental health issues should be the rightful domain of social and behavioral sciences [1].

Schizophrenia has a heterogeneous presentation and has several subcategories including disorganized, simple, catatonic, hebephrenic and paranoid [2]. It is being suggested here that these differences can be explained by differing types and levels of psychosocial privation by significant others from an early age leading to cognitive impairment through inadequate schema and self-schema development in the developing child, among other issues, causing conflict and stress and resulting in disorganized behaviour and impaired self-identity. This is in tandem with absence of suitable and effective intervention from either other family members, community members or professionals. Schizophrenia can be defined as a severe mental disorder, characterized by profound disruptions in thinking, affecting language, perception, and the sense of self. It often includes psychotic experiences, such as hearing voices or delusions [3].

\section{The WHO website states that symptoms can include}

a) Hallucination: Hearing, seeing or feeling things that are not there.

b) Delusion: Fixed false beliefs or suspicions not shared by others in the person's culture and that are firmly held even when there is evidence to the contrary.

c) Abnormal Behaviour: Disorganized behaviour such as wandering aimlessly, mumbling or laughing to self, strange appearance, self-neglect or appearing unkempt.

d) Disorganized Speech: In-coherent or irrelevant speech.

e) Disturbances of Emotions: Marked apathy or disconnect between reported emotion and what is observed such as facial expression or body language.

It can be seen that there are several references to disorganization in this list of categories of behaviour. The significance of this will be demonstrated below.

Human Psychosocial Need: Saunders V [4] has provided a theoretical list of 28 human psychosocial needs. In it she lists the need to be recognized as:

- Species belonging that is, being human.
- With a separate existence and identity to all other humans.

- Belonging to a human group.

- Saunders has further listed other needs relevant to understanding causes of schizophrenia:

- To internalize appropriate norms and values.

- Including the distinction between reality and myth.

- To be able to verify any claim about the nature of reality.

- To be able to organize and systematize knowledge for comprehension of our psychosocial environment.

- To learn about different social categories.

- To develop appropriate schema about those categories.

- To learn rules for differential role performances.

- To learn to recognize the existence of and rules for status differentiation.

- To learn the rules for influence, power and persuasion.

- We need consistency in behaviour and role performance from parents or carers.

- Further needs are:

- Performance feedback:

- For existential reassurance-I exist.

- For group acceptance reasons-I belong.

- For performance competence assessment-I am good at being human.

- Boundaries set for behaviour acceptability.

- Social control mechanisms for maintaining boundaries.

- Social order and mechanisms for maintaining order.

- These are all relevant to identifying the causes of schizophrenia.

Schema Theory and Application: Schemas are cognitive frameworks that systematize, categorize and label information thereby ensuring comprehension about how to interpret our environment and enabling behavioral response. In Piaget's theory of child development, children construct a series of schemas, based on the interactions they experience, to help them understand the world [5].

Schemas consist of shorthand outline views of social and other categories and relationships between categories so that each time an event happens we do not have to once more reorganize the same information. According to Piaget's ideas, schemas represent knowledge about concepts, objects and the relationships they have with other objects, situations, events, sequences of events, actions, and sequences of actions. They affect the way information is interpreted by the individual, but they also adapt and modify with the availability of new information on any one subject.

Schemas can also be explained as mini scripts determining how to understand and respond (behave). There are a few noted studies. For example, Bartlett's [6] War of 


\section{Mental Health \& Human Resilience International Journal}

the Ghosts experiment investigated reconstructive memory. He demonstrated that in re telling an unfamiliar story, participants inserted information that was not present in the original story. However, these changes fitted the culture of the respondent, which was different from the culture of the story teller, thereby demonstrating that because information was re told in specific ways, schemas exist and that there are cultural differences in schemas.

There are also self-schemas which develop as a result of past experience and events. This ties in with ego development; due to a psychosocial need for being valued and respected, people tend to remember more positive comments about the self and ignore more negative ones. However, if all comments are negative, thereby providing negative feedback about the self, then this could potentially have a significant impact on the mental health of a person [7] as it interferes with normal emotional development especially regarding the concept of self. This is significant for onset of schizophrenia.

Schemas develop as a result of consistent experiences which enable rule comprehension to develop and be internalized. Rules cannot be developed without appropriate examples from which to identify patterns which can then be labeled in some appropriate way. In families with offspring who develop schizophrenia, it will be shown below that parents' comments and account of events are absent or untruthful, and or are falsely unflattering to the sufferer, leading to cognitive dissonance and confusion, thereby interfering with schemas and self-schema development and so further leading to disorganized behaviour.

\section{Brief Literature Review of Hypothesized Causes}

Causation is highly contested. Many mental health professionals still want to believe that genes are responsible. Saunders V [1] has provided a definitive evaluation of studies into genetic cause and demonstrated no evidence exists that genes are causative.

Within the discipline of genetics, opinion is that it is not possible for genes to be responsible as there is insufficient variation in gene structure [8-10]. Moreover, studies such as Idaghdour Y, et al. [11] show that our behaviour is responsible for modification of gene expression and that it is our daily experiences that cause change to alleles.

Morgan C, et al. [12] wrote about childhood trauma as a cause of schizophrenia. They define trauma as "a range of severe adverse experiences, including sexual, physical, and emotional abuse, and neglect" (ibid). However, this is a somewhat general definition of trauma. It is not clear as to what specific behaviours constitute various forms of abuse or severe adverse experiences.
They conclude that: The findings from such studies, however, have not been wholly consistent, and a number of methodological limitations mean we should be cautious in over interpreting these (op.cit.:8).

There are many traumatized children in our society and most do not go on to develop schizophrenia. Therefore, trauma as defined above, of itself, could be considered to be a confounding variable. However, if more precise descriptions of behaviours and alternative family structures are considered, then the roles of abuse may well become pertinent, as discussed below.

Social class has also been considered a determinant for schizophrenia by medical researchers. Dunham HW [13] for example, examined the relationship between the incidence of schizophrenia and social class in two culturally contrasting sub-communities in Detroit. They found that, although there was a heavy concentration of schizophrenics in the lowest social class, there were no significant differences in incidence among the other four classes.

In Murray $\mathrm{R}$ [14] four articles considered social determinants of the illness. Bresnahan $M$, et al. [15] in particular observe that social class has long been associated with schizophrenia but that there has been conflicting opinions as to whether social class was a cause or an effect of the illness (2003:5).

Kirkbride J, et al. [16] found that all BME groups in their study had elevated rates of a psychotic disorder after adjustment for age, gender and socio-economic status. However, they concluded that this could not be explained by socio-economic status.

Sociologists would regard ideas about social class and socioeconomic factors as naïve. Social class is a social construct describing differing status and income levels that exist in any one society's hierarchy of prestige. Social constructs are ideas created by humans and therefore have no agency; humans have agency and can cause health problems. If social class were a determinant then most people from a particular class background would be schizophrenic, and they are not.

Hence social class might better be considered as yet another confounding variable, that is, these authors also have made a false positive (Type I) error.

Häfner H, et al. [17] undertook their version of a global demographic analysis of schizophrenia and developed a theory of downward social drift based on results. They further falsely opined that it was unlikely that cultural, social, or ecological factors play a crucial part in the aetiology of 


\section{Mental Health \& Human Resilience International Journal}

schizophrenia (1997: 149).

It has also been noted that there is a high incidence of diagnosed schizophrenia in migrant populations [18-20]. There are several possible explanations for this. One issue may well be cross-cultural differences in diagnosis, including racism on the part of practitioners. Also, it may well be that those already suffering from mental distress want to move to a new environment because they are not coping with their environment, and already have mental health problems before leaving their country of origin.

Psychosis might also be a response to the difficulties encountered as a consequence of migration. If such people come from a society where there are fewer or more rules, or the rules are significantly different from the society of destination, resulting stress could trigger psychotic episodes. That is particularly so for families who move from relaxed rural environments where people have or need little education, to inner urban areas such as London, where there are many new rules to learn. Such a life style is likely to be foreign and stressful to newcomers, who also need to learn a new language, new customs and find jobs. If such people do not have the education and emotional resources to cope because of their upbringing, then it is not surprising that schizophrenia develops in higher proportions than the native-born population.

Many migrants, such as those from the Indian subcontinent and Arab countries, for example, also come from different family structures and often from authoritarian backgrounds where the expectation is that there will be a male head of the family, and that women will obey the head. They arrive in western countries where women have significantly more power and authority, where women are entitled to divorce husbands, and where religion is not important to most. Such differences can be very confusing to those brought up with very different values and belief systems as they contravene learned norms and therefore schemas. But this does not explain why non-migrants develop schizophrenia.

A final environmental influence postulated as causative is family dynamics as has been theorized by Cooper B [18], Laing RD [21], Laing RD, et al. [22], Smail D [23], Snyder F [10], and others.

But LeffJP [24] undertooka study that examined what was called 'expressed emotion'. It was found that many sufferers came from homes where parents were over involved in the development of the child and that parent-child relationships were poor. They found that schizophrenics withdrew socially in order to protect themselves. However, the author was not sufficiently explicit about the environment that caused the withdrawal, although several variables were examined. This demonstrates that using the experimental method is inappropriate for investigating causation because, as will be shown below, schizophrenia is multifactorial and therefore naturalistic observation is a more appropriate research method as multiple and not formerly considered issues can be uncovered.

Moreover, while these studies were not wrong, like Leff JP [24], all did not provide sufficient analysis of parent child interactions to ascertain cause with precision and certainty. Nor was family structure discussed. Cause is much more nuanced and requires greater sophistication of explanation through analyzing and referring to specific types of psychosocial privation and behaviours. Without a proper list of psychosocial needs, it was not possible to state which need was absent in family dynamics, leading many medical scientists to be unconvinced and still believing in genetic cause. Thus, before a definitive and precise analysis of cause was attempted, it was first essential for there to be some sort of definitive list of all human psychosocial needs. This has enabled an adequate description of cause to be achieved for the first time.

\section{Hypothesis Regarding Psychosocial Explanations of Cause}

Primary socialization occurs in the first five years of life. During this period, parents inculcate adequate and appropriate social and cultural norms and values in their children through various psychological mechanisms such as operant and classical conditioning and Bandura's [25] social and cognitive learning. These norms mostly reflect those of the wider society so that there is limited conflict between intra-familial norms and societal wide norms.

But in schizophrenic families, parents lie, obfuscate, play games, abuse, coerce, withhold knowledge (direction) or any combination, or all of these, to such an extent that the child can never be sure what the norms (rules) are and consequently has difficulty in developing appropriate schemas about our psychosocial world and about him or her-self due to a lack of consistency in parental behaviour that enables rule formation as well as negativity in parental attitudes towards the child. Parental norms also conflict with societal norms. The child develops a sense of being worthless (not good at being human) due to not being able to understand or live by societal wide and thereby group norms and withdraws from the external world as self-protection. In tandem, there is an absence of empathy, kindness and affection ('love') in parent-child relations which causes enervation due to being overburdened through either too much attention or not enough attention and trying to sort out fact from fiction, alone and unsupported. 
Moreover, other extended family members either do not exist, or do not provide adequate support for the children, or do not attempt to provide alternative norms and values to the deviant parental norms. This latter issue is also important as not all children who are subjected to parental deviance go on to develop schizophrenia.

\section{Research Method Discussion}

Most medical researchers prefer the experimental method for data collection. Humans are complex organisms with cause of environmental problems often being multifactorial, and therefore use of the experimental method is not appropriate.

When people are observed or interviewed in a clinical setting, they may change their behaviour, or deny that they do certain behaviours (the Hawthorne Effect [26]). Therefore, covert participant observation is the most likely method to circumvent such problems and reveal various previously not considered variables that are important.

However, this raises questions of ethics. Ideally, participants should be able to give informed consent to participating in research and respondent information should be confidential. In this article, ethical standards have been maintained by anonymising information about participants, through pseudonyms and withholding information that would enable identification so that participants' identities are protected. By using covert observation, it has been possible to describe real life behaviours devoid of any form of interference or sense by those concerned that they are being studied and demonstrate conclusively, essential conditions that lead to onset. Indeed, at the time, there was no thought of such data being used for academic purposes. It has only been recently with hind sight that the value of such first-hand observational data has been fully appreciated. Triangulation was used. Data consists of analysis of published government epidemiological data, re-interpretation of published case studies, and analysis of original case studies data.

Interpretative analysis was carried out which required extrapolating information, and also looking for covert messages that informed interpretation. Analysis thus consisted of what Denzin (1989:116) [27] has labeled 'analytic interpretation'.

\section{Data}

\section{Evidence of Social Structure as Supporting Factors}

There is evidence that in western post-industrial countries, schizophrenia rates vary according to age and gender with data revealing similar patterns. Figures 1 \& 2 shows the Canadian rates of hospitalization and British epidemiological rates.

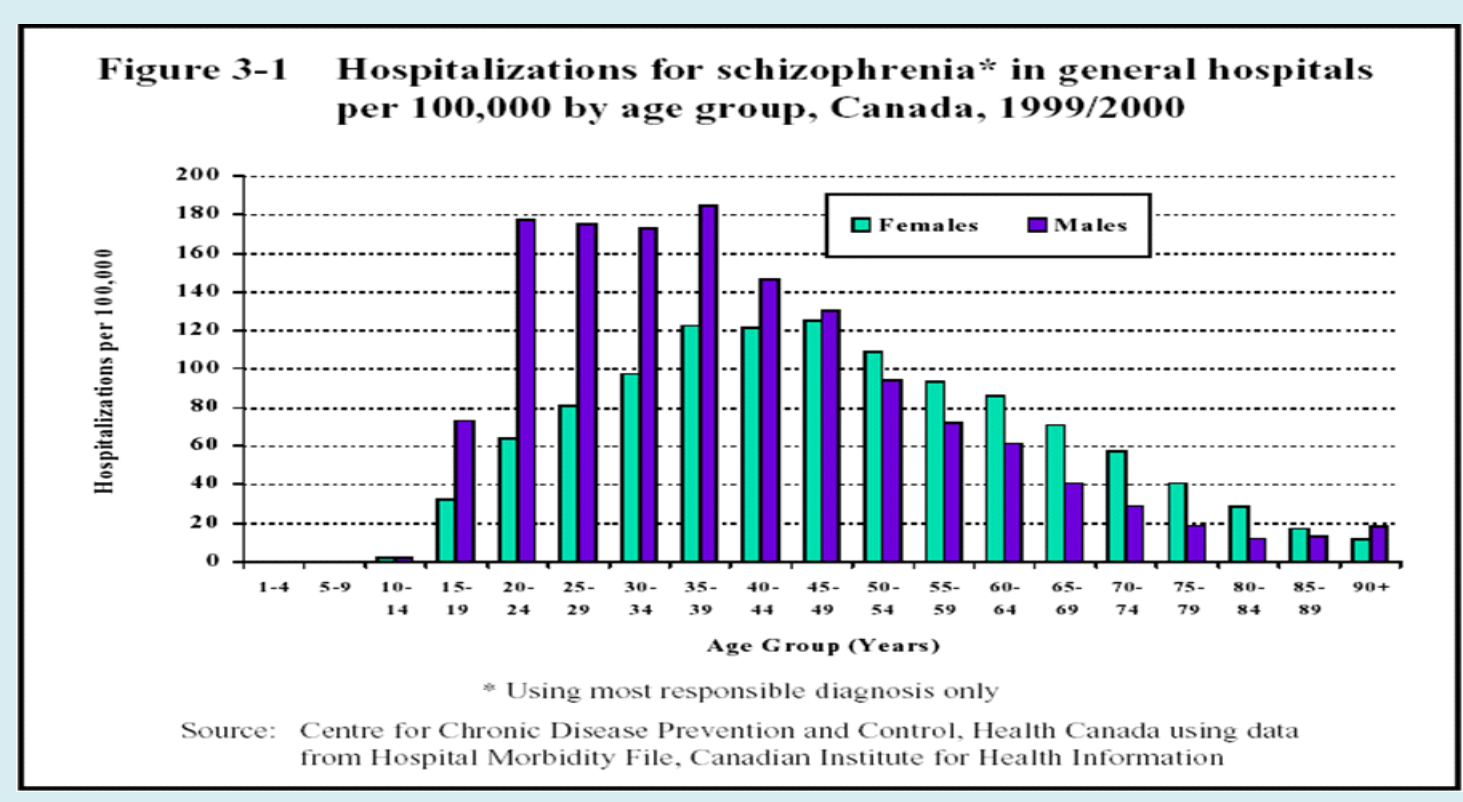

Figure 1: Schizophrenia Hospitalization rates for Canada, 1999-2000, per 100,000. Source: Canadian Institute for Health Information [28]. 


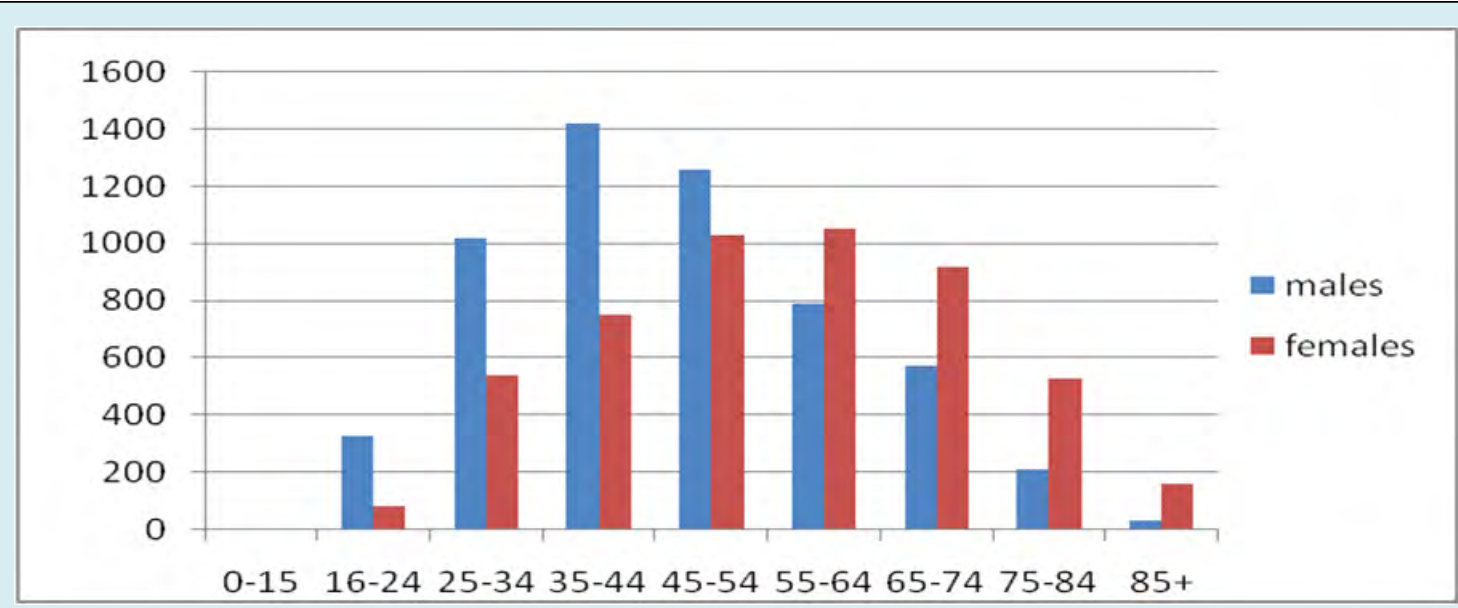

Figure 2: UK epidemiology rates by age cohorts and gender for diagnosed schizophrenia for 1994 to 1998, per 10,000. Source: ONS [29].

It can be seen for both countries that schizophrenia does not begin until early adulthood, that greatest rates are from around thirty to sixty years, decline with age and that highest prevalence rates are in early adulthood. Thus, it mostly affects people in early to mid-adult life. Prevalence rates vary somewhat for males and females, with males generally experiencing earlier onset than females, and declining earlier so that there is a higher prevalence rate for women in old age. This holds true for both sets of data, although overall rates are somewhat higher in the U.K. than in Canada due to Canadian figures being for hospitalization rates, while UK figures are for overall epidemiology rates. Rates are consistently higher among Canadian males aged 20 to 40 than Canadian females demonstrating that men tend to suffer more. Nonetheless there is a similarly shaped inverted curve in both charts which tails off to zero on both sides of maximum values.

Sociology provides interpretations for such patterns. Prevalence rates for schizophrenia in industrialized countries follow role expectation and life course patterns. Prevalence is greater in men throughout most of adulthood [30,31]. Onset is usually in early to mid-twenties and therefore at the beginning of the life stage of adulthood when there are many decisions to be made and new responsibilities to assume. This is when people are completing education or starting families or work. This too is unsurprising as it is still expected that men will be head of the household and largely responsible for the financial well-being of the nuclear family unit, especially while women are engaged in child bearing and child rearing. At this stage many may be engaged in university studies, which is also a stressor. However, by the end of the risk period, male-female rates are equal (op.cit). This can also be explained by life stage issues, such as the stress of coping with raising children and running a home for women. Today also, it is expected that UK women will work which adds to the stress. Rates decline with advance in age so that by age of retirement, incidence is close to zero. This too accords with life stage. By age of retirement, mortgages have usually been paid, children have left home, and work life has or almost has ended, thus removing most important stressors in people's lives [32]. This pattern alone demonstrates that environmental issues must have a significant impact on morbidity rates.

Looking at the chart for Canadian hospitalization rates according to age, it can be seen that for women in particular, greatest incidence occurs during child rearing ages, peaking at when children are likely to be in their teens. With men it begins before average marriage age and peaks at the time when any children are likely to be in their teens. The British epidemiology pattern according to age is slightly different with men peaking at the age when children are likely to be teenagers, but for women, peaking later, when children are likely to be leaving or have left home. The stress here could derive from what sociologists call the 'empty nest syndrome', when children have left home, and many women feel somewhat redundant, having spent so much time, energy and invested so much personal effort in raising their children, only for them to disappear leaving feelings of being not needed anymore.

Figure 3 shows prevalence rates for U.K. schizophrenia from 1994 to 1998. It can be seen that there is a small but steady increase for both men and women, with male rates increasing at a slightly greater rate than for females. This could possibly be explained by greater public awareness about the problem, and improved rates of diagnosis by doctors. Alternative explanations could be that increased stressors in our life styles are causing increased levels of emotional distress. 


\section{Mental Health \& Human Resilience International Journal}

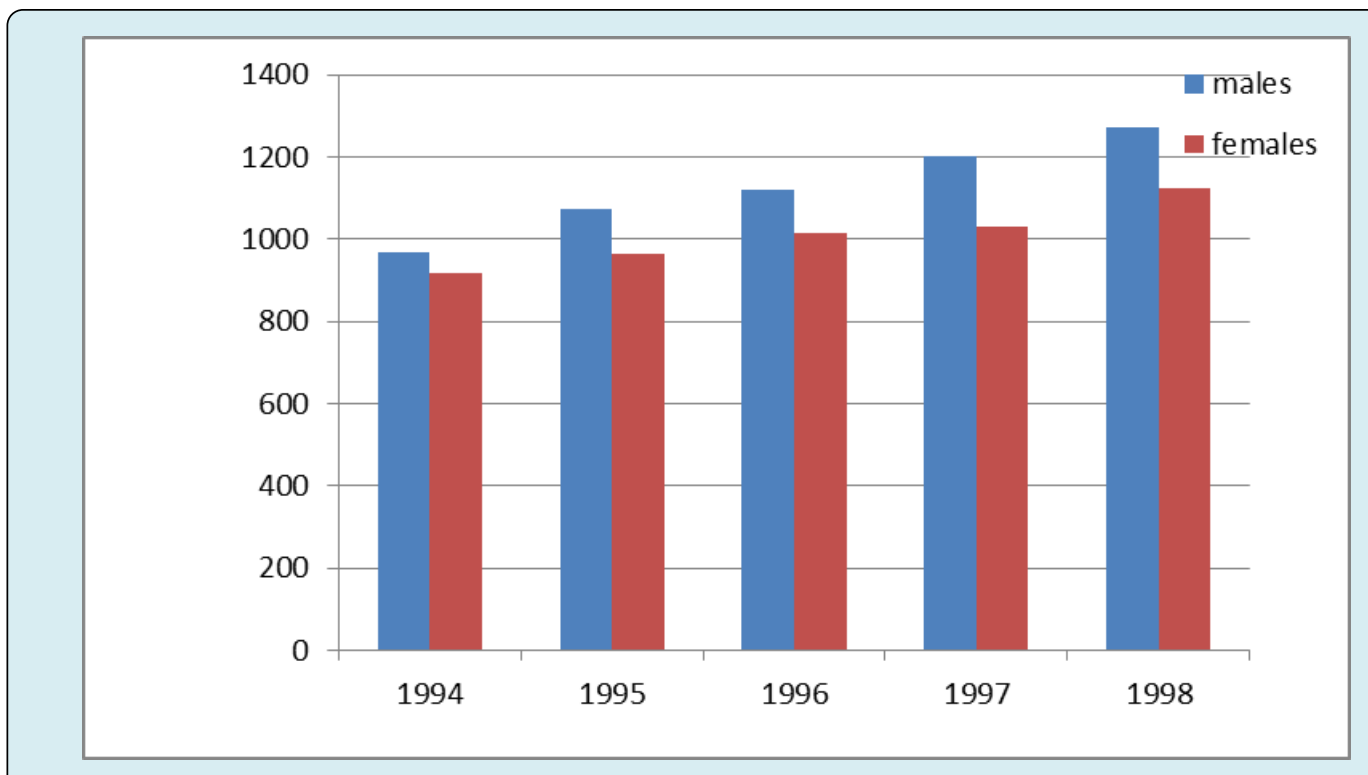

Figure 3: UK schizophrenia epidemiology rates by gender and year, per 10,000, source: ONS.

Hence it can be seen from these three figures that there are marked social patterns of prevalence rates for schizophrenia. If schizophrenia were caused by genes or any other biological factor, then it is improbable that prevalence rates would show such clear social patterns; data would be randomly distributed and they are not.

\section{Evidence from Published Studies}

The first published case is that of Whitwell S, et al. [33] who discussed the case of Mr. B, a 25-year-old white male, who presented with disorganized behaviour. According to these authors, he was an average student at school, and had normal social skills. At age 15 and after he left school (this is an important point), he started becoming withdrawn, and maintaining poor personal hygiene. He could not keep jobs and was unemployed for 10 years before parents called in psychiatric assistance. Moreover, on one occasion, when Mr. $B$ engaged in a slightly dangerous activity using an electric saw to cut wood while balancing across the bannisters, and would not stop at the parents' request, they called the police (2005:398).

This was clear evidence of poor parenting skills, including not being able to communicate effectively with or control their own child. He was diagnosed with simple schizophrenia after extensive testing and eventually prescribed medication which improved his symptoms.

Although details of parenting styles are minimal as evidence is mediated through the researchers, nonetheless it is possible to make certain analytic observations from textual commentary. The first comment is that in our complex post- industrial societies, a fifteen-year-old teenager is still a child and as such has not sufficient life skills to be given autonomy. That is, such a boy still needs to be given support, direction, and action taken by parents to ensure that his behaviour conforms to normal standards (boundary enforcement [4]) as well as showing that the parents cared about him. It appears that the parents did not do that. The impression from the text is that parents were detached, did not provide sufficient direction or attention, boundaries, control of their son or enable son to develop self-control, and that there was a lack of emotional stimulation, warmth, and affection and a total lack of empathy in the home. If a fifteen-year-old does not bath or shower sufficiently, it should be expected that adequate and competent parents who are concerned about the welfare of their child, would put strategies in place to ensure that such behaviour changes. That is, the parents were emotionally unavailable and neglectful, and did not provide adequate information that would enable rule, and therefore, schema formation.

This description ties in with data provided in the previous charts above. His behaviour was normal while at school because his peers provided basic emotional support and it is likely that he would have received appropriate direction and attention from other normal teenagers and possibly from teachers too. Moreover, before leaving school, provision of essential physical conditions for survival are provided by the family and school so the child has no need to provide for himself. The problem began after leaving school, when the peer group was no longer in existence, therefore his only support group had gone, and he was expected to take responsibility but could not. There may well have been other parental behaviours leading to the withdrawal, but have 


\section{Mental Health \& Human Resilience International Journal}

been unrecorded by the researchers.

Let us examine part of a real-life conversation between seven-year-old Betty and the author. This serves as an example of normalcy and control, with which to compare behaviour from other case studies.

Betty was the daughter of a neighbour. The author was in a public space when Betty initiated the conversation:

"B: What are you doing?

Author: Climbing stairs.

B: No you're not. What are you doing?

Author: Eating chocolate.

B (with glee): No you're not. What are you doing?

Author: Alright then, I am putting on my space suit because I am going to Mars.

B (with laughter, emphasis and dramatic posturing): No... you're...not! What are you REALLY doing?"

This child is a normal, mentally healthy seven-year-old, who is already sufficiently sure of herself, and her knowledge of the world to initiate contact with and to contradict a much older adult, and to do so with confidence. Although only seven years old, she was able to accurately interpret the author's behaviour. She had already internalized many appropriate norms and values leading to appropriate schema development, and as such was able to function effectively in a range of relationships (roles) due to parent child transactions being 'straight' [34]. This has resulted in an emotionally healthy child who is able to effectively handle mild teasing.

Examples of conversations between Betty and her mother are here:

'Mum: I told you to put your lunch box in your school bag. You have not done it. Do it now.'

And, after school one day:

'Mum: go and put your good shoes on. We are going to grandma's house.

B: why are we going to grandma's house?

Mum: because it is your aunt Suzy's birthday and we are holding a surprise party for her'

It can be seen that Mum provides for all Betty's physical and psychosocial needs, is direct, factual, and sets clear boundaries to behaviour as well as expectations regarding conformity to her instructions with truthful explanations as to why she was giving instructions. She does not make any negative personal remarks about Betty herself, but is focused on achieving family organizational outcome. Her attitudes and behaviours are consistent and her order is followed by an explanation for the need to abide by her order thereby leading to compliance. This has led Betty to understand her psychosocial environment and therefore develop appropriate schemas as Mum is consistent, well organized and rational. The power structure is normal with mother in control and providing benign and competent direction leading to Betty feeling secure and self-confident. Extended family relationships are important.

Compare the dialogue with Betty with the following. When Maya Abbott [22] stated that she was worried about her exams, her mother said that she was not. When Maya announced that she masturbated, Dad said that she did not. Maya said that blackness came over her when she was eight. Her parents said it did not. Maya said that her parents tried to stop her reading. They firstly said that was nonsense, then added that she had to be torn away from her books, thereby tacitly admitting that she was correct. While speaking, they were winking and smirking with one another, thereby covertly communicating that they were engaging in a form of game playing which would somehow disadvantage their daughter, thereby displaying an absence of kindness and empathy towards her. These are selected examples of habitual parent child interactions in the Abbott family from Maya's early years.

Similar interactions occurred in the Head family (op. cit.: 201) [22]. Jean Head said she was often depressed and frightened. Her parents said she was always happy. Jean said family disharmony was so complete she could not tell her parents anything while the parents denied that there was any disharmony. Her parents said she never wanted to do things such as go to the cinema, have sex before marriage, go to dances, and go to restaurants, while Jean said she did all these things. Even Jean's husband claimed that she was full of confidence and very capable while Jean said she was very unsure of herself. He also stated that they saw things the same way while Jean said she saw many things differently.

Here Maya and Jean are correctly stating facts about themselves, but the parents contradict their daughters thereby coercing, obfuscating and causing confusion and conflict in the mind of their child who, because this was habitual behaviour by the parents over many years, cannot be sure what is and is not reality, and as a result, their ability to function adequately in the external world is curtailed due to having their authority undermined and schema development interfered with. Personal authority arises from knowledge of social norms, and therefore ability to act appropriately and even with sophistication, in the external world.

Although the dialogue with Betty is brief, several important matters are revealed. Firstly, it is the child who confidently and correctly contradicts the adult about reality, when the adult obfuscates, thereby reversing roles. The author was playing the role of child while Betty was playing 


\section{Mental Health \& Human Resilience International Journal}

the role of adult [34]. She was able to accurately evaluate the information provided by another adult and assess whether it was true or false. This is because Betty's parents correctly describe reality to her so that she has internalized relevant norms and is able to tell the difference between fact and fiction with certainty. This enables her to engage in other relationships with confidence knowing that she is good at being human, that is, she is able to act with authority in social relations. Maya and Jean's parents lie to their child about family behaviours. Betty is merely seven years old and normal. Maya and Jean are now adults and psychotic. Betty is outgoing and investigates the external world with confidence, enthusiasm and curiosity. Maya and Jean have retreated inside themselves in confusion and apathy.

Yet a further and different example is that of the Field family [22]. June Field was only fifteen when she experienced a psychotic episode. She was admitted to hospital in a rigid catatonic stupor. June was born with a congenital dislocation of the hip which necessitated various admissions to hospital and operations.

\section{Mother stated:}

"I know Sylvia [sister] was older but we all used to take June out because I always took her everywhere with me, always. Naturally I would. I didn't ever leave her...... As I say, she was always a very boisterous child, she's always been such a happy little girl - haven't you June?

June: $\mathrm{mmm}$.

Mother: Yes, you have dear." (ibid: 148)

\section{The Clinical Notes of the Interviewer State}

"It is important to realize that Mrs. Field's picture of June was, of course, never true. June's whole life was totally unknown to her mother. She felt shy and self-conscious, unsure of herself, but big for her age and active in swimming and other sports that she had undertaken to master her prolonged childhood crippled condition....Although active, she was not independent for, as she told us, she had largely complied with her mother, and had seldom dared to contradict her. She did however begin to go out with boys when she was thirteen while pretending to be at Church Club." (p. 151).

Again, we have a situation where the mother imposes her etic on her daughter which is completely false. Change came when June attended a church camp for a month and was therefore completely away from her mother. When she returned she had changed in a 'bad' way according to Mrs. Field. But according to the researcher:

"she began for the first time to give some expression to how she really felt about herself, her mother, her schoolwork, God, other people, and so on, by ordinary standards, to a very subdued extent" (ibid).
But her mother saw this development of self as an expression of mental illness and said so. This is coercion and emotional blackmail. The consequence of this was that June began to withdraw and then became catatonic. She also told doctors that she was being poisoned which they labeled a 'delusion'. During this period her mother nursed her for three weeks and:

"It was the most harmonious phase directly observed by us in their relationship. Conflict only began when June, from our point of view, began to recover.... In the period of recovery, almost every advance made by June was opposed vehemently by her mother, who consistently regarded as steps back what to us and to June were steps forward" (p152).

June was not able to be an autonomous human with a separate identity, personality and world view to that of her mother. The mother lied consistently about reality to June and medical personnel, always trying to coerce others into accepting her etic as the norm. It was only when June was able to escape from her mother for a month that she experienced life with normal humans and rebelled somewhat. Mother could not cope with the resulting assertiveness and applied pressure to June that lead to her breakdown. That is, attention and direction were excessive and inappropriate, and June's development was atrophied by the mother's need to dominate and control her daughter. June was also not permitted time and space to herself in the external world (another psychosocial need) due to excessive, coercive and damaging attention from her mother and so retreated into her inner world and became catatonic.

In this case study, catatonia is associated with excessive, suffocating and abusive attention, arguably due to June feeling unable to escape as she was still a child dependent on her mother, and therefore led to the onset of a catatonic state. By becoming catatonic June was able to escape from her mother.

Thirty-six-year-old Claire Church believed that she had an atom bomb inside her.

"She was subject to ideas of reference and persecution and her outbursts were sometimes directed towards the person or persons (usually unknown) who were tormenting her (calling her a prostitute, cutting her up into little pieces, torturing her without mercy)." (op.cit.: 73)

She believed that her mother did not want her to grow up, and would not let her live her own life and have ideas of her own about the world. Claire became afraid to express her own feelings but 'followed her way instead of my own' (op. cit:77). Mother dismissed all of Claire's statements as being part of her 'illnesses. The parents insisted that they were a happy and affectionate family, but the evidence provided in interviews was very different to the beliefs expressed. Her 


\section{Mental Health \& Human Resilience International Journal}

brother Michael had also been schizophrenic from the age of sixteen. The atom bomb idea was clearly a metaphor for Claire's explosive emotional state. She was probably correct in her allegation that her mother did not want her to grow up and lead her own life; many mothers have this problem (personal observations). The voices were metaphors for the impact that her mother's meddlesome and moralizing attitudes were having on Claire's emotional state.

All eleven cases in Laing and Esterson contain the same theme. There is a distortion of reality by the parents but for different reasons. Moreover, all parents without exception is self-absorbed, lack empathy, and do not provide their child's essential psychosocial needs as set out above. The child is expected to fit in with adult demands, who are impervious to the fact that children have needs and wants different from those of adults due to different biological and emotional levels of maturation. There is moreover, a complete lack of introspection and insight and understanding of themselves and their own behaviour and consequently all parents engage in the ego defense mechanism of denial [35].

Laing RD [21] also wrote about family dynamics from an existential perspective, using phenomenology and psychoanalysis as a framework. In his book on the "divided self" (2010 version, pp 69-73), he discusses several case studies, two of those being David and Peter. A close analysis of text reveals that the relationship between parents and each child was not conventional. The fact that David was pleased when his mother died is revealing; this is not the normal reaction of a ten-year-old. Laing has made some excellent observations, but nonetheless has omitted crucial information.

What Laing seems not to have realized is that in all probability, David's mother dominated and controlled him to such an extent that he was not able to become a person in his own right, and because he therefore had no schema regarding being an autonomous discrete human, after she died he took over her role of shopping for food, cooking, doing embroidery and so on, because he became his mother, even dressing in women's clothing at times, all due to extreme repression in early life. As a result, he had a severe identity problem, and was not able to cope without his mother. His integrity as a discrete human had not been made possible by his mother and being recognized as a separate human is a psychosocial need for normal development as stated above.

The case study of Peter (pp. 120-133) [36] is somewhat different. Peter believed that there was a bad smell coming from himself and from around the genital area. According to Peter's uncle, Peter's parents were inseparable, had been married ten years before Peter arrived, and "treated him as though he wasn't there" (p 120). His mother had never received affection herself and therefore could not give Peter any. He was never cuddled or played with and cried a lot when a baby. His mother was pretty, dressed up a lot and admired herself, that is, was narcissistic. His father although fond of him, beat and belittled him. Peter himself felt that he was unwanted and that his parents "had never forgiven him for being born" ( $p$ 122). He felt that he was nobody and "on the fringe of being". He felt that: "he was not really alive and that anyway he was of no value and had hardly the right to the pretension of having life" (p 125, my emphasis). Clearly his psychosocial needs as set out in the introduction above had not been met.

Laing RD [36] also discussed the case study of 'Jane', who was trapped in family games. The only way that her parents would communicate with one another was through Jane herself. Mother would say to Jane: 'tell your father to pass the salt', and father would then reply to Jane: 'tell her to get it herself'. Laing perceived family interactions as controlling and the individual becomes the victim of 'collusive pairing' and double binds, making life unbearable, and this was the source of the psychosis. Yet again the themes in this family reflect earlier cases. The parents are self-absorbed and distort reality while ignoring the existence of their child as a person in her own right and in need of provision of normality through direction in order to develop into a mature and autonomous adult with appropriate schemas.

While Laing is not entirely wrong when he claims that it is the games that parents play that cause schizophrenia, he is not right either, because he has missed important points. It is not the presence of games per se, that are causative, but absence of normality so that the child is consistently and only provided with either a distorted perception of the world and of him or herself, or an absence of information, leading to an inability to construct appropriate schemas [37]. This results in disorganized behaviour as the child does not know how to systematize information about him or her and each's psychosocial environment due to not having normal schema construction modelling provided by parents.

In Bandura's [25,38,39] social and cognitive learning theory, children learn from the environment through the process of observational learning and interpretation. Children observe the behaviour of others, including parents and siblings, around them and these behaviours become models for the child's own behaviour. Children encode such behaviours into schema. Sometime later they may imitate the behaviour they have observed. If the behaviour of parents is deviant or inconsistent, that is, does not reflect reality elsewhere or is absent, this interferes with the ability to codify and imitate parental behaviours. As Bandura states: 'Modelling is not merely a process of behavioral mimicry. Modelling influences convey rules for generative and 


\section{Mental Health \& Human Resilience International Journal}

innovative behaviour. This higher level observational learning is achieved through abstract modelling. In abstract modelling, observers extract the rules governing specific judgments or actions differing in context but embodying the same underlying rule. Once people extract the rules they can use them to judge things and generate new courses of behaviour that fit the prototype but go beyond what they have seen or heard.' (1999:25) [39].

That is, Bandura is discussing schema formation but using somewhat different terminology to that of Piaget due to approaching the issue from a different academic perspective. Nonetheless, Bandura's account helps to explain that when behaviour is inconsistent or indeed, absent, it prevents the ability to form general rules, that is, schemas, leading to confused thinking. Rule formation requires provision of consistent examples before being comprehended and internalized. In the case of absent examples, such as when parents do not interact with a child as in the case of Mr. B, this too, can lead to an inability to extrapolate information, internalize rules and form schemas.

Moreover, while games are in situ, the child does not feel valued, his or her integrity as a separate human is not respected, does not feel good at being human, does not receive adult intervention to maintain homeostasis, does not receive warmth and affection, or empathy and understanding, and is not able to express his or her own feelings adequately. In addition, there is a lack of control over significant others, that is, most of the needs listed in the orange and yellow sections of a figure by Saunders V [4] on psychosocial needs are missing.

Thus, games are a mechanism or process used by some adults to substitute for normal parent child interaction with the motive of intentionally, albeit sub-consciously, preventing the provision of normal psychosocial needs in order to prevent development into an autonomous adult. They are a means to an end, that end being a way of wielding power.

Even the detachment of the parents of Mr. B can be a game. They did not provide attention and direction, and stood back and observed the outcome being aware that without their help, he would not develop into an autonomous adult while expecting him to do so. It took them ten years before they sought psychiatric assistance. It is likely that the aim here is also to maintain a child in a dependent state so that he does not leave his parents. So even if there are no word games that Laing, and Laing and Esterson, describe, action or its absence, can also be a game.

While Jane's parents were at war, they were ignoring the needs of Jane. She was a pawn in their games. So, she was not being provided with appropriate or adequate attention, or adequate and appropriate direction. She did not exist as a person in her own right, with needs and wants of her own. The parents were selfish and self-absorbed, totally involved in their little power games to the detriment of Jane's personal development. The norms and values being provided were inappropriate and inadequate. She was not being permitted to develop emotional independence. There appeared to be no meaningful emotional contact with her parents. The situation was causing stress, thereby removing homeostasis, and the adults were colluding in ensuring that homeostasis was never present. There was no one to support and talk to Jane, while parents expected her to get on with life as if all were normal. Jane felt overburdened, emasculated, and unable to cope with daily living requirements and so retreated into her inner world where she thought of herself as a tennis ball.

This delusion is a metaphor for the dynamics of family relationships as were the delusions of Peter and Claire Church. As Laing too noted, it is likely that all schizophrenic delusions are some form of metaphor for the psychosocial conditions being experienced by the person with the delusions and as such, are an attempt to communicate internal states to the external world.

Moreover, it is likely that all the hebephrenic utterances and word salads of schizophrenics are attempts at communication but have difficulty due to faulty schemas and no self-confidence. It is the inappropriate attitude of medical personnel who insist that the behaviour of schizophrenics is meaningless that results in adverse attitudes by doctors.

An example is a quote in Laing RD [22] about Kraepelin's treatment of a catatonic patient. In 1905, Kraepelinintroduced an 18-year-old man to his class of medical students as an example of catatonic schizophrenia, and asked him to say where he was, among other questions. The young man was arguably not amused at the lack of respect and consideration of his feelings by the medics and uttered a rant which is perfectly intelligible to a non-medical person. Kraepelin declared that the young man was 'inaccessible' and stated that 'although he undoubtedly understood all the questions he has not given us a single piece of useful information. His talk was only a series of disconnected sentences having no relation whatsoever to the general situation' (ibid.). This was factually incorrect, that is, Kraepelin lied to students about what his patient had said, and thereby teaching medical students that being patronizing and lying is how to interact with psychotic patients.

At the least, this demonstrated gross insensitivity to the young man's feelings about being the chief exhibit in a freak show, which he undoubtedly was with a group of medical student peers gawping at him, not to mention grossly misinterpreting the meaning of his words. Kraepelin was 


\section{Mental Health \& Human Resilience International Journal}

imposing his etic on the situation, and as such displayed prejudice and a lack of empathy and understanding towards the young man.

However, telling lies and being patronizing is exactly the type of interaction that often occurs between parents and schizophrenic children as we saw above leading to onset of psychosis. By ignoring the content of the young man's words Kraepelin was covertly providing performance feedback which was 'you do not belong, are not human and are being rejected'.

In all of these case studies, parents have repressed their offspring for their own selfish wants, due to their own inadequacies and insecurities. The reasons and motives behind such parental behaviour are varied. Many of these parents cannot cope with the idea that their child must become an adult one day, and leave them. They then subconsciously devise strategies to ensure that the child never becomes an adult, thereby leaving the parent in a position of power and authority over the children. This means that the parent will forever be needed and will never feel redundant, a problem for many adults as children approach the time when they might leave home.

The fact that the mother daughter relationship was most harmonious when June was ill supports the hypothesis that the mother was behaving in such a way as to always cause her child to be dependent and never leave her. Once the child has left home, the parent experiences 'empty nest syndrome'. This requires serious self-assessment about purpose in life and focusing on activities other than parenting, which has been the parental focus for so many years. Many parents feel that they have no purpose in life other than to raise and support spouse and offspring. Once that purpose has been completed, there is no plan B for post-retirement and old age. Hence there is a desire to postpone the day when this emptiness will present itself.

Other parents are worried about being left alone if children leave home, as they do not have the maturity or resources to be able to cope on their own. They devise strategies for making their child or children dependent on the parent so that they never leave home.

Still more parents (such as Peter's family) feel obliged to comply with the social expectation that all adults should marry and produce at least one child, but do not want this for themselves. Consequently, any child to such a marriage is neglected, often belittled for existing, and these parents continue to exist wherever possible in their own world, with little or no compromise for any offspring, who is largely expected to raise him or herself with disastrous consequences.
Yet a further category of parent is those who are already confused about various relationships, have some sort of psychological abnormality themselves, such as a personality disorder or schizophrenia even, thereby resulting in much conflict and dysfunction. Although such parents may intend being benign, due to mental confusion or even ignorance, there are inadequacies. Again, self-absorption ensures neglect and even abuse of any children, leading to psychosis.

A further case study consists of a family known to the author through the community. The Hudsons consisted of a married couple, Louise (a housewife) and Terry and their two daughters. This couple had strong relationships with Louise's parents, Louise's married siblings and Terry's siblings. Louise had been diagnosed by her GP as suffering from anxiety and depression. However, to those with whom she had regular contact it was apparent that she also had very poor concentration, was not capable of holding down a job, lacked motivation and was slow, had little eye contact and her thinking was confused and disorganized leading to distorted accounts of events and ideas. That is, in all probability she was mildly schizophrenic. It was equally apparent that Louise was paranoid due to being argumentative, untruthful, uncooperative, manipulative and distrustful. As an example of her mind-set, she was heard to claim in hysterical rants on more than one occasion: 'all men are evil'.

She was physically and emotionally abusive towards both daughters. If a daughter asked a question any response was either vague, a non sequitur, ignored, or the child was verbally abused for daring to expect her mother to pay her attention, leaving the girls in a state of confusion and distress. She would shout and verbally abuse both girls, calling them unflattering names (e.g. 'you asinine creature'), and sometimes hit them. She would expect help in the kitchen but then criticize any such help.

In short, the way she treated both girls, was like the way that 'Peter's' parents treated him, see above.

Here is an example of observed question and response between mother and eldest daughter aged around five years old:

'D: How does a train driver know which station to stop at? Mother: Just because he does.'

This is an example of withholding information about how the world works, thereby demonstrating contempt for the daughter as a discrete human with her own psychosocial needs.

Terry refused to collude with Louise causing considerable familial conflict. He would scold her forcefully sometimes when she verbally abused the younger daughter in particular, as the verbal abuse started when the daughter 


\section{Mental Health \& Human Resilience International Journal}

was only a toddler. Terry would frequently pick the child up and give her a cuddle in response to Louise's behaviour. Further criticisms came from her own mother, her husband's siblings and her own siblings as well as the family GP. At one stage, during primary school years, there was talk by the GP of the girls being taken into care, but it did not happen although a social worker visited regularly for around a year. Louise was advised many times by family members to see a psychiatrist but refused.

The girls often stayed with their grandparents especially during school holidays while Louise's mother often visited and undertook much housework that Louise herself was not able to do due to being confused and withdrawn. Aunts and uncles organized family excursions to the beach and similar, or visited and spent time with the girls, so that there was constant contact with other normal adults and cousins. The result was that as adults the girls did not develop schizophrenia, although the younger girl had other mental health problems.

A further community case study consists of Elsie Smith and her son, Giles. At that time, Elsie was in her fifties, well educated, never married, self-employed and foreign born. She had migrated many years previously and therefore had no family nearby. However, she had a son aged 30 .

When the author first met Elsie, her reaction was to wonder about the well-being of any possible children that Elsie might have due to the way that Elsie engaged in conversations, which were difficult due to the level of obfuscation and non sequiturs that existed. The author later was informed that at the time, Elsie had one son, Giles, who was in a psychiatric hospital having been diagnosed with schizophrenia. This was not a surprise. On one occasion at least, Elsie told the author that she was aggrieved that Giles was schizophrenic. Her belief was that cause was somehow due to Giles himself and he was intentionally victimizing her.

Some months later, after Giles was discharged into his mother's care, the author met Giles and asked him why he thought he suffered from schizophrenia. His response was to let forth a highly emotional and negative rant about his mother's lack of competence as a parent.

Here is an example of a brief piece of dialogue between the author and Elsie, demonstrating non sequitur.

'A: What time is it?

E: I never mow my lawn. It makes my garden look more natural.'

Louise and Elsie interacted with others in a similar way. They obfuscated, refused to provide essential information to others including their developing children, and were dominating and controlling. In interactions with others, both often played the role of parent [34]. In transactional analysis terms, transactions were usually 'crossed' The difference in outcome for the children was marked. Louise's daughters did not suffer from schizophrenia while Elsie's son did. This appears to demonstrate the potentially important role that extended families can play in child development when parents are not coping and why some children do not become schizophrenic in spite of abusive family relationships. Much depends on the type and extent of abuse. Hence cause is complex and multifactorial.

\section{Results}

Evidence from Figures 1 to 3 supports the evidence from specific case studies cited above; it is incontrovertible that schizophrenia is an environmental problem. There is no genuine evidence of biological cause.

Evidence from published and unpublished case studies reveals that several human psychosocial needs as listed by Saunders V [4] above, are not being met. In all cases, there is a lack of respect by parents for the sufferer (performance feedback) leading sufferers to believe they are not good at being human; in tandem with this there is a lack of empathy and affection (love). All parents breach boundaries. In all cases there is a failure by parents to provide adequate and appropriate direction, including lack of consistency of appropriate information, thereby prejudicing the child's ability to organize information, develop rules and schemas, and consequently to comprehend reality, develop normally, and function adequately in relationships. The child is thereby denied any authority or self-belief in his or her ability to function as a human. In some cases, there is an absence of sufferers having a separate existence and identity to all other humans. Family relationships are coercive leading to stress and withdrawal.

Levels of attention vary. In some there is excessive and abusive attention, while in others there is neglect. In all, the level of attention therefore is inappropriate to the needs of the sufferer.

It is also apparent that extended family contact can potentially be valuable. From available evidence, it appears that where there was significant extended family intervention, the children did not develop schizophrenia.

Because schizophrenic sufferers are internally located, they make poor primary caregivers. Where households consist of the nuclear family only, and a schizophrenic mother alone is the primary caregiver, it is likely that there will be serious mental health problems for the next generation because the schizophrenic mother is unable to behave in an 


\section{Mental Health \& Human Resilience International Journal}

organized way that leads to rule comprehension and creation and schema formation in a child. This can lead medical researchers, such as Millar JK, et al. [41] to mistakenly claim a genetic cause when cause is the intergenerational transmission of abnormal familial culture through learned deviant behaviour.

In addition, the above explains why some people experience psychotic episodes as adults. It occurs as a result of stress caused by conflict between two value systems and therefore conflicting sets of schemas and a perceived inability to resolve such conflict possibly due to imagined or actual coercion, causing the person to have feelings of being powerless and worthless. Pressure to conform to societal norms under difficult personal circumstances leading to stress may well cause some more vulnerable people to descend into psychosis. The person believes that he or she cannot cope or function adequately and so retreats from rejection and failure. Among Western European capitalist societies, it is a social value that failure is unacceptable, and therefore it is expected that a 'failed' human will be rejected by others, leading to fear of failure.

It has also been noted that the rate of schizophrenia in migrant families in particular, is high. These findings potentially explain why those families that migrate to the UK are more at risk; this is partly due to conflicting norms and values between society of origin and society of destination, thereby causing stress, conflict and confusion. This is particularly so when there is coercion to adhere to noninternalized norms in society of destination. Those who are reliant on authority figures (possibly existing in an agentic state [42]) such as religious or tribal leaders, to tell them how to behave and what is or is not socially acceptable, cannot by themselves form rules (schema) under different conditions as they have never been able to do so in society of origin, feel powerless, not good at being human (because they do not understand their psychosocial environment) and withdraw.

\section{Discussion}

Human neonates are not precocial; they are extremely dependent on human adults for survival for many years while they acquire physical and emotional maturity and are thereby subject to parental supervision alone for some years. In our post-modern European societies, household structure is usually that of the isolated nuclear family, with parents and dependent children living together in one home [29]. This makes parental responsibility and skills highly important as there are no other adults present to mitigate any parental deficiencies in child rearing.

From an evolutionary perspective, Homo Sapiens is a social animal, and we are programmed through our genes which have evolved over many hundreds of thousands of years, to want to participate in groups for survival reasons and consequently we fear rejection as separation from the group would limit survival. In order to avoid any such rejection from the group, all humans have a basic, genetically programmed, need to conform to group norms and values.

Our psychosocial environment is also very complex, requiring many years of internalizing appropriate norms and values in order to adequately participate in a variety of relationships in a range of social institutions. Therefore, the socially accepted role of parents is to provide adequate and appropriate physical and psychosocial conditions under which to rear children so that they mature into healthy and adequately functioning adults. This necessitates parents being both (a) benign and (b) reasonably competent, and if not then the child's physical and psychosocial well-being and even survival is threatened. That is, as a society, we expect that normative parental behaviour will avoid damaging a child.

Because parents usually have no training for their role as parents, most muddle through as best as are able, and so it would be unreasonable to expect all parents to be perfect. Therefore, providing a standard for acceptable parenting needs to assert the minimum requirement, namely, that of avoiding damage to their child.

Any interaction with a child carries not only overt messages, but covert or unspoken and implied messages. The refusal by parents to provide direction carries the covert message that the child is not of sufficient value for them to bother, that they will not intervene to assist, and that they do not care about the consequences to the child. Any such refusal therefore must have a devastating impact on a child's sense of self-worth.

The parents of schizophrenics are neither (a) benign nor (b) competent. They do not conform to societal wide expectations regarding standards in parenting. They lie about reality to their child for their own purposes, as also did Kraepelin above, without considering the effects of such lies on the developing child. But the child accurately perceives the world through five senses. This results in cognitive dissonance in the child that leads to conflict, confusion and the development of disorganized ideas and behaviour. That is, the parents' actions are deviant; the child's reaction to the deviance is a logical and to-be-expected response [21,24].

Because mental health professionals have never fully examined and accurately labeled various phenomena associated with relationship pathology, they do not comprehend and so apply inappropriate, pejorative labels such as 'delusions', 'hallucinations' and similar. 


\section{Mental Health \& Human Resilience International Journal}

In perceiving herself as a tennis ball in a game of mixed doubles, Jane had accurately understood her function in the family. Peter, in believing that there was a bad smell coming from his genitals was articulating the idea that his parents did not want him (genitals being the source of new life) and thought badly of him. Both were indirectly describing their problem using idioms. Peter had never behaved badly and therefore his parents did not accurately reflect this in terms of their attitudes towards him. He knew that he did not deserve their opprobrium therefore he became confused. June in believing that she was being poisoned accurately described the nature of the relationship with her mother: it was toxic because the mother was poisoning June's perception of reality with her lies and insistence on dominance so that the lies were accepted as the norm and took the place of June's world view which had been formed as a result of normal relationships experienced in school and church groups. Thus, as Laing correctly commented, delusions are metaphors which succinctly summarize the child's emotional state Vis a Vis their parents.

Some parents also make the child feel worthless through failing to provide basic psychosocial needs, such as in the cases of Mr. B, 'Peter' and 'Jane' above. Such strategies are intentional forms of social control by some parents all of whom without exception, lack kindness and empathy, further essential psychosocial needs. These parents are not aware of the consequences of their selfishness, and are not prepared when their child becomes psychotic, with some feeling aggrieved (personal communication, see Elsie Smith, above). They lack adequate parenting skills but many cannot accept this. Most are weak and inadequate individuals, with problems of their own. To have to accept that they have not fulfilled their responsibilities as parents adequately, is difficult. Nonetheless, these parents have provided inadequate socialization of such magnitude that the resulting privation causes that which we currently label 'psychosis'.

Privation to such an extent is child abuse. Yet when interviewing parents, as cited in Laing and Esterson, the mental health professionals seemed reluctant to either offer therapy to the parents or remonstrate with them. June Field aged fifteen, became catatonic, but staff did not seem to do anything about the mother and indeed the text gave the impression that they colluded with her and expected June to fit in with her. Such an abused child should ideally be removed from the family home and housed in more suitable accommodation at least until parental attitudes change significantly.

This is supported by comments made by a former patient himself. MacPherson M [40] states:

'In my opinion, the origins of schizophrenia lay in a very confused sense of self that manifests in a model of very low self-esteem. The boundaries of the individual's self are confused with the self of the mother and/or father. My impression is that the individuals know that their personal recovery from their world is very different from a normal world as experienced in general society. This psychological state leads to a splitting of emotions in the individual.'

And:

'Recovery from schizophrenia is possible when one develops a healthy self and establishes firm psychological boundaries with each of their parents. The role of the parents is pushed to the background and replaced with the self.'

These comments support the ideas that parents are coercive, dominating and controlling, breach boundaries, and behave in such a way as to cause the schizophrenic child to not be able to form appropriate positive self-schema in tandem with not being able to exist autonomously, leading to low self-esteem and impaired self-development.

\section{Clinical Implications}

Fully understanding cause has clinical implications for prevention and treatment. Only when pathological relationships are stopped will it be possible for recovery to happen, as implied by McPherson M [40] above. Parents need to be encouraged to consider their own behaviours, preferably through therapy. Psychiatric staff gives the impression of not being able to handle the emotional abuse that parents inflict on children. Attitudes and training need to change.

\section{Conclusion}

Cause is environmental and multifactorial due to there being many relevant human psychosocial needs, and a range of social structures, involved. However, the two most important factors are firstly, absence of normality, in parent-child interactions ensuring psychosocial privation. This is replaced by presence of distorted rules regarding relationships and statuses of sufferers, including consistent psychosocial boundary violations, by nuclear family primary carers leading to an inability to comprehend environment and subsequently to organize thoughts and actions. Parentchild transactions must be 'straight'. This leads to confidence in children as was demonstrated with the case study of Betty. Due to abnormal behaviour, it is likely that parents themselves have disordered personalities or other mental health problems. From personal experience, it is being suggested that the two most likely personality disorders are paranoid and or narcissistic due to parents being controlling, defensive, inconsistent, self-absorbed and untruthful. This is a possible risk factor. 
Second is the extent of involvement and support, or lack thereof, by significant others, especially, but not limited to, extended family members. Therefore, social isolation of parents is a second possible risk factor. Those who suffer from schizophrenia do so as a result of a range of forms of emotional abuse. It needs to be recognized by professionals that such a person has been abused and wherever possible remove him or her from any such abusive situation and place him or her in an environment where there is positive support and therapy. Preventing schizophrenia would benefit society at many levels including the economy and the NHS as sufferers need psychiatric intervention and cannot work due to poor concentration. Evidence supports the validity of Saunders' [4] theoretical list of psychosocial needs. Schizophrenia is not the imponderable that medical science has portrayed for decades; it is comprehensible and preventable. It is also not a medical problem; it is a psychosocial problem. Therefore, it is no accident that the definitive cause of schizophrenia has been established by a social scientist and not a medical scientist; it has only been possible to achieve this through using social science paradigms and research methods (Figure 4).

\section{PSYCHOSOCIAL CAUSES OF SCHIZOPHRENIA}
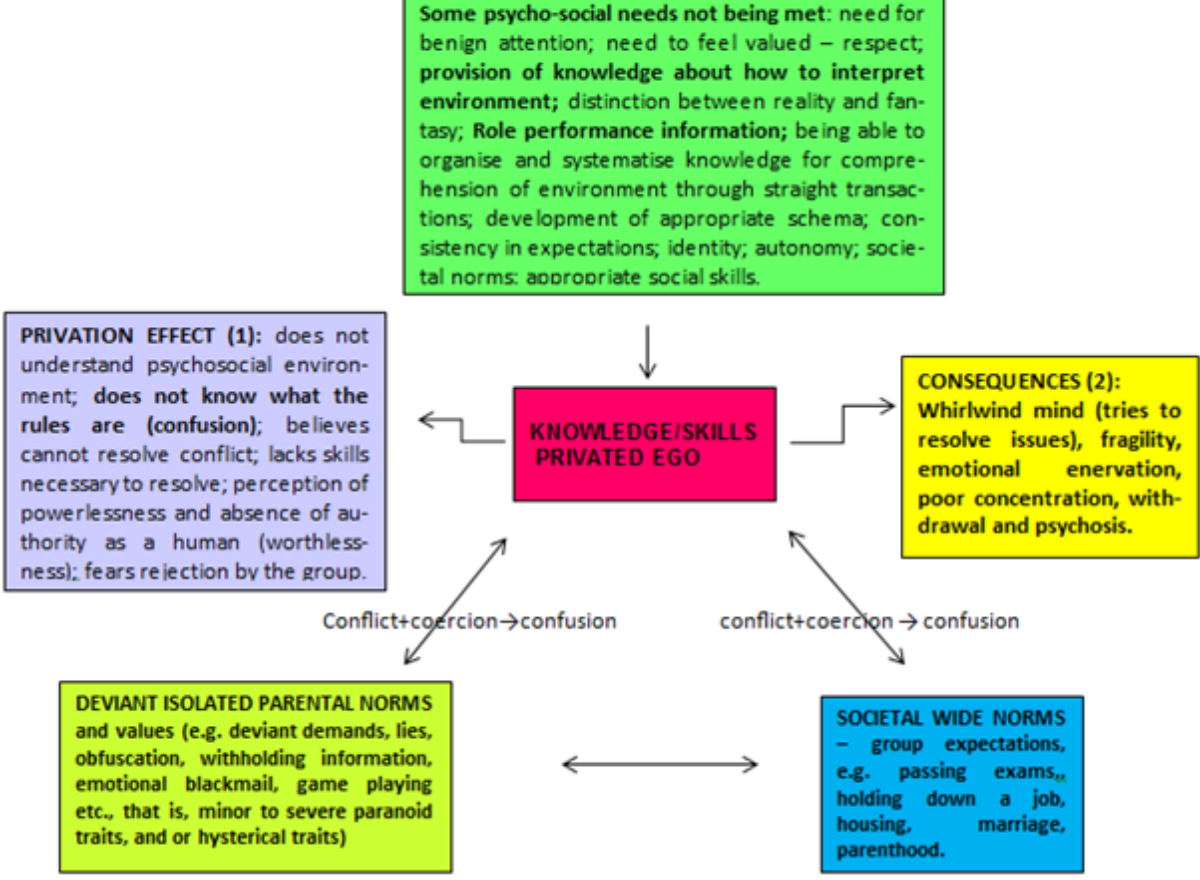

Figure 4: Dynamics of three competing and seemingly non-reconcilable psychosocial forces leading to psychosis.

\section{References}

1. Saunders V (2021) The naked emperor syndrome revisited: An Evaluation of Schizophrenia Gene Studies Research Methods. Int J Psychiatr Res 4(1): 1-7.

2. Peralta V, Cuesta MJ (2001) How Many and Which Are the Psychopathological Dimensions in Schizophrenia? Issues Influencing Their Ascertainment. Schizophr Res 49(3): 269-285.

3. ICD for a detailed account of all forms of schizophrenia including symptoms of each type.
4. Saunders V (2021) A theoretical list of all human psychosocial needs. Int J R Sci Res 12:1.

5. Georgeon OR, Ritter FE (2011) An intrinsically motivated schema mechanism to model and simulate emergent cognition. Cognitive Systems Research 15(16): 73-92.

6. Bartlett F (1932) Remembering: A Study in Experimental and Social Psychology. Cambridge: Cambridge University Press.

7. Storey AL (1998) Self-esteem and memory for favorable and unfavorable personality feedback. Personality and Social Psychology Bulletin 24(1): 51-64. 


\section{Mental Health \& Human Resilience International Journal}

8. Ridley M (2004) Nature versus Nurture: Genes, Experience and what makes us Human. New York and London: Harper Perennial.

9. Joseph J (2004) The gene illusion: genetic research in psychiatry and psychology under the microscope. USA: Algora Publishing.

10. Snyder F (2011) The Unholy Grail.

11. Idaghdour Y, John DS, Sami JJ, Gibson G (2008) A Genome wide Gene Expression Signature of Environmental Geography in Leukocytes of Moroccan Amazighs. PloS Genetics 4(4): 1000052.

12. Morgan C, Fisher H (2007) Environmental Factors in Schizophrenia: Childhood Trauma-A Critical Review. Schizophr Bull 33(1): 3-10.

13. Dunham HW (1964) Social class and schizophrenia. American Journal of Orthopsychiatry 34(4): 634-642.

14. Murray R (2003) The Epidemiology of Schizophrenia. Cambridge: UCP.

15. Bresnahan M, Menezes P, Varma V, Susser E (2003) Geographical variation in incidence, course and outcome of schizophrenia: A comparison of developing and developed countries. The epidemiology of schizophrenia, pp: 18-33.

16. Kirkbride J, Jeremy WC, Craig Morgan, Paul Fearon, Paola Dazzan, et al. (2010) Translating the epidemiology of psychosis into public mental health: evidence, challenges and future prospects. J Public Ment Health 9(2): 4-14.

17. Häfner H, an der Heiden W (1997) Epidemiology of schizophrenia. Can J Psychiatry 42(2): 139-151.

18. Cooper B (2005) Immigration and schizophrenia: the social causation hypothesis revisited. Br J Psychiatry 186: 361-363.

19. Heinrichs RW (2001) In search of madness. New York: OUP.

20. McGrath J, Sukanta Saha, Joy Welham, Ossama ES, MacCauley C, et al. (2004) A systematic review of the incidence of schizophrenia: the distribution of rates and the influence of sex, urbanicity, migrant status and methodology. BMC Med 2: 13.

21. Laing RD (1965) The Divided Self: An Existential Study in Sanity and Madness. Harmondsworth: Penguin.

22. Laing RD, Esterson A $(1964,1970)$ Sanity, madness and the family: families of schizophrenics. Harmondsworth: Penguin Books.
23. Smail D (1969) The Treatment of Mental Illness Science, Faith and the Therapeutic Personality. London: University of London Press, pp: 192.

24. Leff JP (1976) Schizophrenia and sensitivity to the family environment. Schizophrenia Bulletin 2(4): 566-574.

25. Bandura A (1986) Social foundations of thought and action: A social cognitive theory. Prentice-Hall, Inc.

26. Emanuel JM, William JB (1997) Research in Education and the Behavioral Sciences: Concepts and Methods. Madison, WI: Brown \& Benchmark.

27. Denzin N (1989) Interpretive Interactionism. London: Sage.

28. Canadian Institute for Health Information (2001) Hospitalization rates for Canada, 1999-2000, per 100,000. A Report on Mental Illnesses in Canada. Centre for Chronic disease prevention and control. pp: 51 .

29. ONS (2011) Social Trends, 41. London: OHMS.

30. Göttesman II, Shields J (1982) Schizophrenia: The Epigenetic Puzzle. Cambridge: Cambridge UP Pp: 258.

31. Aleman A, Kahn RS, Selten JP (2003) Sex Differences in the Risk of Schizophrenia: Evidence From Meta-Analysis. Arch Gen Psychiatry 60(6): 565-571.

32. Holmes TH, Rahe RH (1967) The social readjustment rating scale. J Psychosom Res 11(2): 213-218.

33. Whitwell S, Bramham J, Moriarty J (2005) Simple schizophrenia or disorganisation? A case report and review of the literature. Advances in Psychiatric Treatment 11(6): 398-403.

34. Berne E (1964) The games people play. New York: Grove Press.

35. Freud A (1937) The Ego and the Mechanisms of Defense. London: Hogarth Press and Institute of Psycho-Analysis.

36. Laing RD (1971) The Obvious in Cooper D (Edn.), The Dialectics of Liberation. Harmondsworth: Penguin.

37. Piaget J (1936) Origins of intelligence in the child. London: Routledge \& Kegan Paul.

38. Bandura A (1962) Social Learning through Imitation. Univer Nebraska Press pp: 211-274.

39. Bandura A (1999) Social cognitive theory: an agentic perspective. Asian journal of social psychology 2(1): 2144.

40. MacPherson M (2009) Psychological causes of schizophrenia. Schizophr Bull 35(2): 284-286. 
41. Millar JK, Anderson S, Taylor MS, Devon RS, Christie S, et al. (2000) Disruption of two novel genes by a translocation co-segregating with schizophrenia. Hum Mol Genet 9(9): 1415-1423.
42. Milgram S (1963) Behavioural study of obedience. Journal of Abnormal and Social Psychology 67(4): 371378. 